\title{
Microstructure evaluation of titanate based layered perovskites: constrained vs. free sintering
}

Senos, A.M.R. , Amaral, L. ${ }^{*}{ }^{* *}$, Selvaraj, N.B*, Fernandes, M. ${ }^{*}$, Jamin, C. ${ }^{* * *}$, Guillon, O. ${ }^{* * *, * * *}$, Reaney, I. ****** and Vilarinho, P.M.

"Department of Materials and Ceramics Engineering, CICECO, University of Aveiro, 3810-193 Aveiro, PORTUGAL

**Materials Electrochemistry Group, ICEMS, Instituto Superior Técnico, Universidade de Lisboa, 1049-001

Lisboa, PORTUGAL

${ }^{* * * *}$ Institute of Materials Science, Technische Universität Darmstadt, Darmstadt D-64287, GERMANY

${ }^{* * * *}$ Institute of Materials Science and Technology, Friedrich-Schiller-Universität Jena, Jena, D-07743, GERMANY

***** Department of Engineering Materials, University of Sheffield, Sheffield, S1 3JD, UK

Email: $\underline{\text { anamor@ua.pt }}$

Grain growth can be influenced by many factors such as pressure, temperature and atmosphere during sintering. In previous studies by our group [1-2] it was well identified that the grain growth in bulk and thick films of titanate-based layered perovskites is distinctive. In the constrained sintering of thick films, the substrate was found to enhance grain growth. A better understanding of the mechanism of grain growth in the thick films and bulk ceramics can be achieved by detailed microstructure analysis. In this work we report the microstructure analysis of $\mathrm{BaLa}_{4} \mathrm{Ti}_{4} \mathrm{O}_{15}$ (BLT) as bulk and constrained sintered thick films on $\mathrm{Pt}$ substrates.

BLT powder was prepared by conventional solid state route with calcination at $1330^{\circ} \mathrm{C}$ for $3 \mathrm{~h}$. Bulk samples were shaped by uniaxial pressing of BLT powders at $100 \mathrm{MPa}$. Thick films were deposited on the top of Pt foil by electrophoretic deposition from a powder suspension in ethanol and nitric acid [1]. Films and bulk samples were sintered at $1500{ }^{\circ} \mathrm{C}$ for $180 \mathrm{~min}$. Cross-section and top view Scanning Electron Microscopy (SEM) photographs (XL 30 FEG, Philips Electronic Instruments, Mahwah, NJ and S4100, Hitachi, Tokyo, Japan) were acquired for microstructure evaluation. For the grain growth analysis, polished cross-sections were chemically etched using a 0.3 vol\% HF-6 vol\% $\mathrm{HNO}_{3}$ solution for $30 \mathrm{~s}$. SEM micrographs were analyzed using ImageJ software (NIH, USA) to determine density, pore and grain size, grain aspect ratio and orientation factor (corresponding to the fraction of weighted cumulative lengths of grains with orientation in the ranges $0^{\circ}-30^{\circ}$ and $150^{\circ}-180^{\circ}$, i.e., oriented almost parallel to the substrate in film or perpendicular to the shaping pressure direction in bulk). Detailed Transmission Electron Microscopy (TEM) analysis (Hitachi 9000, Tokyo, Japan) of the grain boundary (GB) structure was also performed.

The SEM micrographs presented in Fig. 1 revealed that highly dense anisotropic microstructures with platelet-like grains are observed in both films and bulk. However, and despite the fact that the microstructure of the green state is equivalent in films and bulk, quite distinct microstructures were observed after sintering: equivalent densities but larger grains and pores, together with increased grain elongation and orientation, are observed in the films (see Table 1). These observations point to a significant effect of the substrate on the grain growth during sintering, increasing either the GB mobility or the driving force. In agreement, TEM analysis of the sintered films showed thick GBs with high level of structural disorder, as illustrated in Fig. 2, which are neither crystalline nor amorphous and can be compared to GB complexions of high mobility [3]. 
The authors are grateful to Fundação para a Ciência e a Tecnologia (FCT), Fundo Europeu de Desenvolvimento Regional (FEDER), QREN-COMPETE, the European Union, and the Associate Laboratory CICECO (PEst-C/CTM/LA0011/2013) for funding support.

[1] Amaral, L. et al., J. Am. Ceram. Soc., 95, 3781-3787, 2012.

[2] Amaral, L. et al., J. Eur. Ceram. Soc., 33, 1801-1808, 2013.

[3] Dillon, S. J. et al., Acta Mater. 55, 6208-6218, 2007.

Table 1: Microstructure parameters of BLT samples.

\begin{tabular}{|l|l|l|l|l|l|}
\hline & $\begin{array}{l}\text { Relative } \\
\text { density }(\%)\end{array}$ & $\begin{array}{l}\text { Median } \\
\text { grain area } \\
\left(\mu \mathrm{m}^{2}\right)\end{array}$ & $\begin{array}{l}\text { Median pore } \\
\text { area }\left(\mu \mathrm{m}^{2}\right)\end{array}$ & $\begin{array}{l}\text { Median } \\
\text { grain aspect } \\
\text { ratio }\end{array}$ & $\begin{array}{l}\text { Grain } \\
\text { orientation } \\
\text { factor }\end{array}$ \\
\hline BLT film & 96 & 0.85 & 0.096 & 2.27 & 0.70 \\
\hline Bulk & 97 & 0.39 & 0.063 & 2.05 & 0.53 \\
\hline
\end{tabular}
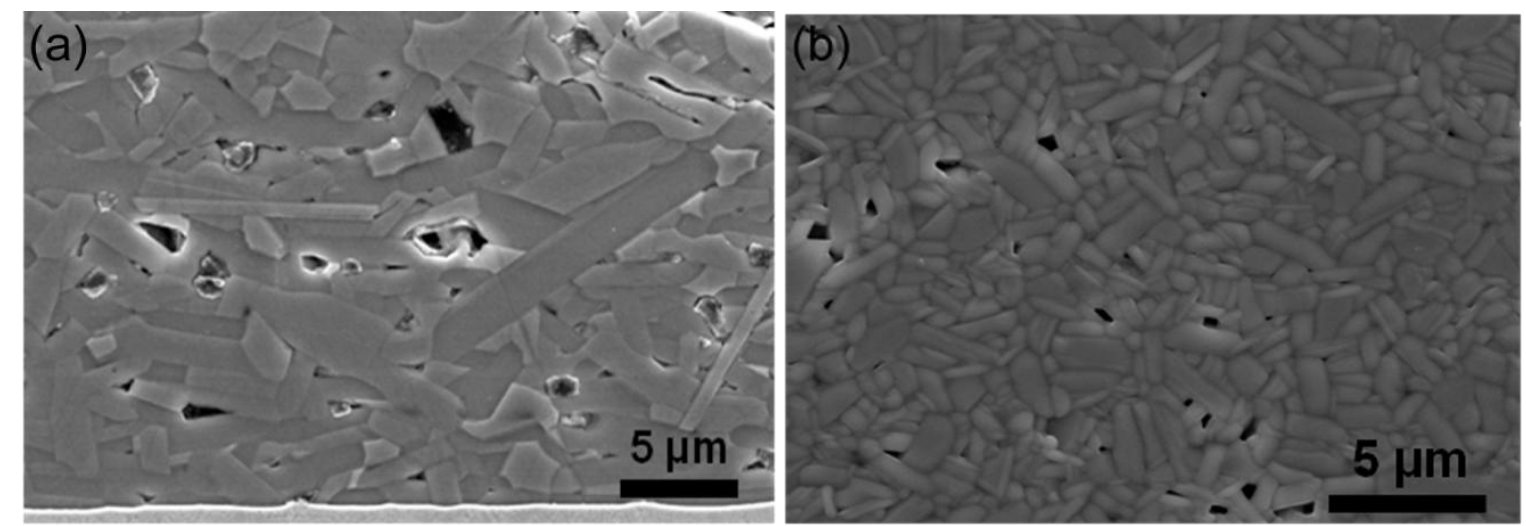

Figure 1. SEM microstructures of BLT: (a) film cross-section and (b) bulk fracture surface.

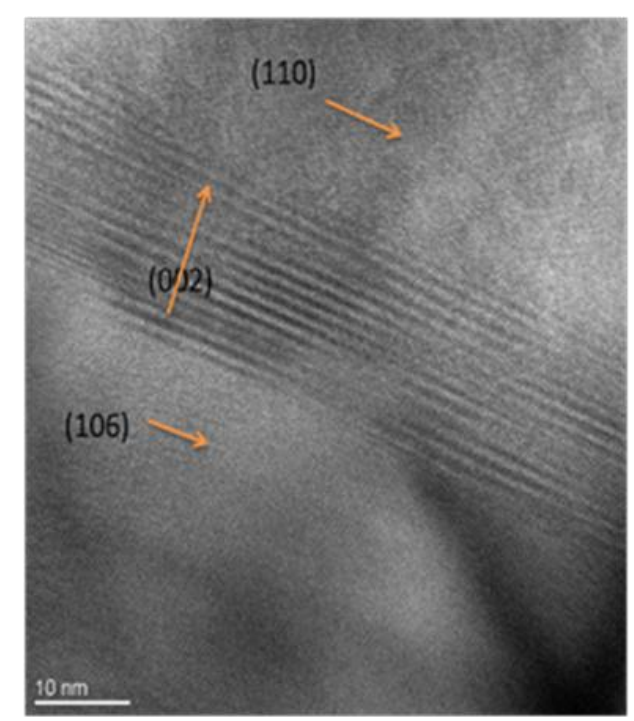

Figure 2. TEM image of a low angle GB in BLT film. 